\title{
BMJ Open What factors influence older people's intention to enrol in nursing homes? A cross-sectional observational study in Shanghai, China
}

\author{
Mengyun Luo, ${ }^{1}$ Yajiong Xue, ${ }^{2}$ Shunxing Zhang, ${ }^{3}$ Yuanyuan Dong, ${ }^{1}$ Dandan Mo, ${ }^{1}$ \\ Wei Dong, ${ }^{1}$ Kun Qian, ${ }^{1}$ Yue Fang, ${ }^{1}$ Huigang Liang, ${ }^{2}$ Zhiruo Zhang ${ }^{1}$
}

To cite: Luo M, Xue Y, Zhang S, et al. What factors influence older people's intention to enrol in nursing homes? A crosssectional observational study in Shanghai, China. BMJ Open 2018;8:e21741. doi:10.1136/ bmjopen-2018-021741

- Prepublication history and additional material for this paper are available online. To view these files, please visit the journal online (http://dx.doi org/10.1136/bmjopen-2018021741).

$\mathrm{ML}$ and $\mathrm{YX}$ contributed equally.

Received 17 January 2018 Revised 10 July 2018 Accepted 3 August 2018

Check for updates

(c) Author(s) (or their employer(s)) 2018. Re-use permitted under CC BY-NC. No commercial re-use. See rights and permissions. Published by BMJ.

${ }^{1}$ School of Medicine, Shanghai Jiaotong University, Shanghai, China

${ }^{2}$ College of Business, East Carolina University, Greenville, North Carolina, USA

${ }^{3}$ Scarsdale High School,

Scarsdale, New York, USA

Correspondence to Dr Huigang Liang; huigang.liang@gmail.com and Dr Zhiruo Zhang;

zhangzhiruo@sjtu.edu.cn

\section{ABSTRACT}

Objectives Given the increasing need of long-term care and the low occupancy rate of nursing homes in Shanghai, this study attempts to explore what factors influence older people's intention to enrol in nursing homes.

Design A cross-sectional observational study based on the theory of reasoned action was conducted. Survey data were collected from subjects during face-to-face interviews. Structural equation modelling was employed for data analysis.

Setting This study was conducted in six community health service centres in Shanghai, China. Two service centres were selected in urban, suburban and rural areas, respectively.

Participants A total of 641 Shanghai residents aged over 60 were surveyed.

Results Structural equation modelling analysis showed that the research model fits the data well $\left(\chi^{2} / \mathrm{df}=2.948\right.$, Comparative Fit Index $=0.972$ and root mean squared error of approximation $=0.055)$. Attitude $(\beta=0.41$, $p<0.01)$, subjective norm $(\beta=0.28, p<0.01)$ and valueadded service $(\beta=0.16, p<0.01)$ were directly associated with enrolment intention, explaining $32 \%$ of variance in intention. Attitude was significantly influenced by Ioneliness $(\beta=-0.08, p<0.05)$, self-efficacy $(\beta=0.32$, $p<0.01)$ and stigma $(\beta=-0.24, p<0.01)$, while subjective norm was significantly influenced by life satisfaction $(\beta=-0.15, p<0.01)$ and stigma $(\beta=-0.43, p<0.01)$. Conclusions This study advances knowledge regarding the influencing factors of older people's intention to enrol in nursing homes. It suggests that Chinese older persons perceived stigma has the strongest indirect effect on their intention to enrol in nursing homes. This is unique to the Chinese context and has practical implications for eldercare in China and other Asian countries with similar sociocultural contexts.

\section{INTRODUCTION}

With the largest ageing population in the world, China is facing unprecedented challenges in eldercare. Shanghai, the first city facing negative population growth change in China, entered the ageing societyin 1979 . $^{1}$ The number of people aged over 60 in Shanghai

\section{Strengths and limitations of this study}

- This study is among the first to understand why Chinese older people are willing to enrol in nursing homes from the theory of reasoned action perspective.

- A stratified sampling strategy was used to recruit subjects from urban, suburban and rural areas of Shanghai to increase the sample's representativeness.

- Data were analysed by using structural equation modelling which can yield more accurate results.

- A limitation is that the cross-sectional survey data cannot support causal relationships among variables.

reached 4.58 million, approximately $31.6 \%$ of the city population, at the end of $2016 .^{2}$ It is projected there will be over 5.4 million older people in Shanghai by 2020. ${ }^{3}$ An older person could stay home or in eldercare institutions. However, as the employment pressure increases, home care for older people leads to physical and emotional burden on the family. The burden heightens as the older person continues to age and becomes less independent. Family caregivers can be relieved by placing the older person in a nursing home. Moreover, in China, most family caregivers are usually housewives and daughters-in-law without professional training on home care. The average quality of such home care tends to be inferior to the institutionalised eldercare services. In contrast, nursing homes can provide professional care by licensed caregiving staffs. Therefore, enrolling in nursing homes is an advisable choice for both the older person and the family.

At present, there are 702 registered nursing homes and 132800 nursing home beds in Shanghai. ${ }^{2}$ The bed to person ratio is 32.9 beds per 1000 older persons, which is far less 
than other countries such as the USA. ${ }^{4}$ Meanwhile, only about $70 \%$ of the beds are occupied, and the occupancy rate of non-government funded nursing homes is as low as 52\%. ${ }^{5}$ Empty beds in nursing homes indicate a waste of valuable resources. Thus, it is imperative to understand why the nursing home enrolment in Shanghai is low. Given that an older person needs to first agree to live in a nursing home before the enrolment can subsequently occur, the low willingness to enrol in nursing homes might have contributed to the high percentage of vacancies in Shanghai's nursing homes. In fact, a recent survey showed that only $11.2 \%$ of the older residents in Shanghai were willing to stay in nursing homes. ${ }^{6}$ Hence, the purpose of this study is to understand what factors influence older people's intention to live in nursing homes in Shanghai.

Past research on the predictors of intention to enrol in nursing homes was mostly based on Andersen's behavioural model of health service utilisation. ${ }^{7}$ Variables that have been examined mainly included individual-level and interpersonal-level variables. At the individual level, sociodemographic variables such as age, gender, education and income have often been found as predictors of intention to use long-term care facilities. ${ }^{8}$ Health status, including medical status, physical impairment and cognitive impairment, was also important determinants of nursing home entry. ${ }^{9} 10$ At the interpersonal level, perceived social support and nursing home placement experience of close friends were found to be associated with nursing home admission. ${ }^{11}$

To understand older people's willingness to enrol in nursing homes, we develop a research model drawing from the theory of reasoned action (TRA), a widely adopted theory designed to predict volitional health behaviours by using sociocognitive determinants. ${ }^{12}$ According to TRA, a person's behavioural intention is a function of two determinants, attitude and subjective norm. Attitude reflects the individual's positive or negative evaluation of performing the target behaviour, while subjective norm is the person's perception of what important others expect him/her to or not to engage in the target behaviour. Generally, people intend to perform a behaviour when they evaluate it positively and when they believe that important others think they should perform it. In this study, the target behaviour is enrolling in nursing homes, and we thus propose that attitude and subjective norm are primary determinants of enrolment intention. Moreover, we propose that the value-added service provided by nursing homes is another salient determinant of intention to enrol in nursing homes. The literature on eldercare and nursing homes also suggests four salient variables as antecedents of attitude and subjective norm: loneliness, self-efficacy, life satisfaction and stigma. ${ }^{13-16}$ Specifically, older persons who are lonely, low in self-efficacy and stigmatised by living in nursing homes tend to have a negative attitude towards nursing homes, ${ }^{13} 1416$ whereas those who are unsatisfied with life and not stigmatised by nursing homes tend to have a positive subjective norm of living in nursing homes. ${ }^{14} 16$ Integrating TRA and the existing literature, we propose the following hypotheses:

Hypothesis 1a: Older persons' intention to enrol in nursing homes is influenced by their attitude towards nursing homes.

Hypothesis 1b: Older persons' intention to enrol in nursing homes is influenced by their subjective norm of nursing homes.

Hypothesis 1c: Older persons' intention to enrol in nursing homes is influenced by value-added services provided by nursing homes.

Hypothesis 2a: Older persons' attitude towards nursing homes is influenced by their loneliness.

Hypothesis 2b: Older persons' attitude towards nursing homes is influenced by their self-efficacy of living in nursing homes.

Hypothesis 2c: Older persons' attitude towards nursing homes is influenced by their perceived stigma of living in nursing homes.

Hypothesis 3a: Older persons' subjective norm of nursing homes is influenced by their life satisfaction.

Hypothesis 3b: Older persons' subjective norm of nursing homes is influenced by their perceived stigma of living in nursing homes.

\section{METHODS}

\section{Participants}

A sample of Shanghai residents aged over 60 and not staying in nursing homes was recruited. Subjects who had hearing, cognition or communication problems were excluded. The final sample included 641 subjects. The sample size was determined by a power analysis using GPower V.3.1. To be conservative, we assumed a small effect size $\left(f^{2}=0.022\right)$. The sample size of 641 would give us power of 0.80 at the 0.05 alpha level.

\section{Setting}

We recruited subjects in six community health service centres in Shanghai from October to December 2016. To avoid biases related to geographical locations, we employed a stratification sampling strategy to select two centres from urban areas, two from suburban areas and two from rural areas. A sign was displayed at the entrance of each service centre to describe the purpose of this study. Individuals were approached and invited to participate.

\section{Procedure}

A questionnaire was developed based on the literature. The questionnaire was reviewed by an expert panel of experienced public health and behavioural scholars to ensure its content validity. Minor wording revisions were made to improve clarity and readability of the questions. To increase data accuracy, the questionnaires were completed during face-to-face interviews. The data collection lasted for 2 weeks at each site. During each day, we greeted every patient at the entrance of each site. We used a few simple questions to evaluate the patient's hearing, communication, and cognitive capabilities and those who 


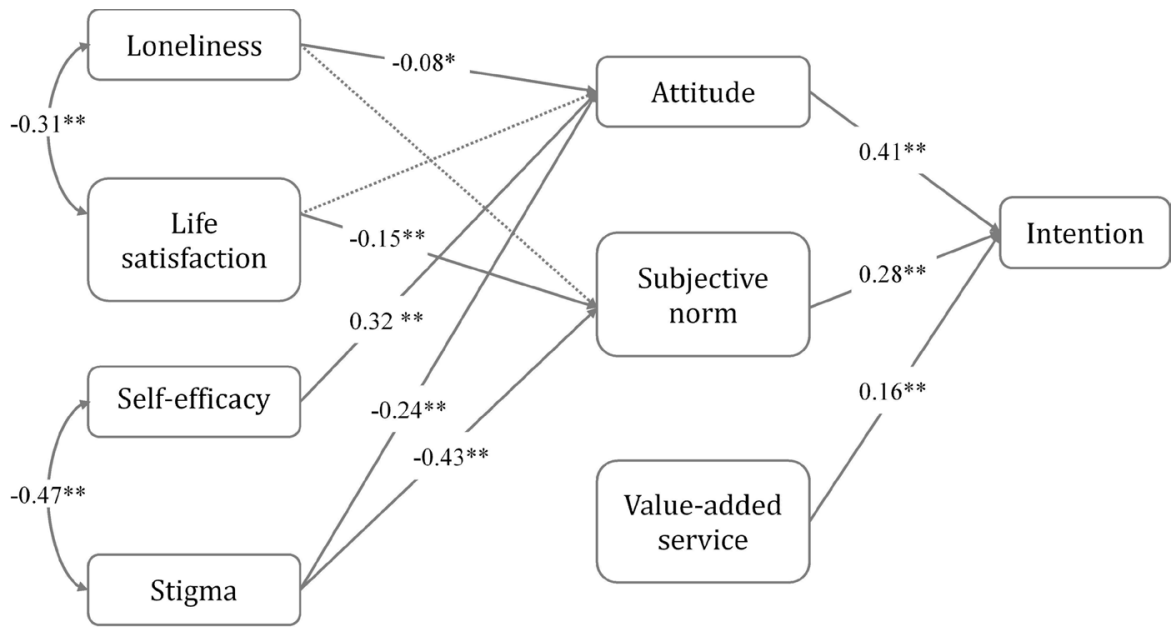

met the inclusion criteria were invited to participate in our study. If the subject agreed to participate, we asked him or her to sign a consent form before the data collection interview. The interview was then conducted in a private room, during which a research assistant asked questions on the questionnaire and filled in the questionnaire based on the subject's responses.

\section{Patient and public involvement}

The elderly people were involved in the design of this study in two ways. First, to gain an initial understanding about older people and inhibitors of nursing home enrolment before deciding what factors to be included in the research model, we interviewed several older people living in nursing homes and several living at home. Second, we asked several older people to fill out the survey as a pretest to make sure that the questions are understandable to them. Although in some studies patients were highly involved as both participants and partners, ${ }^{17}$ in this study, patients were only involved as participants. Because the survey was anonymous, the results of this study were not planned to be disseminated to the participants.

\section{Variables}

This study included one outcome variable, intention to enrol in nursing homes and seven predictors including attitude, subjective norm, value-added service, loneliness, life satisfaction, self-efficacy and stigma. As shown in figure 1, attitude, subjective norm and value-added service are direct predictors of intention, while loneliness, life satisfaction, self-efficacy and stigma are indirect predictors whose effects are mediated by attitude and subjective norm.

\section{Measurements}

Sociodemographic information collected included sex, age, income, marital status, education level, health status, residence status and number of offspring. Health status was measured by one question: 'How do you evaluate your overall health in comparison with an average person at your age?' with five response choices $(1=$ verybad, $2=$ bad,
$3=$ average, $4=$ good, $5=$ very good). We measured the older people's intention by asking participants one question: 'Are you willing to enrol in the nursing homes in the future?' We measured loneliness with two items (Cronbach's alpha $=0.907$ ) derived from the UCLA Loneliness Scale (V.3). ${ }^{18}$ Life satisfaction was assessed with the two items (Cronbach's alpha=0.982) derived from the Satisfaction of Life Scale. ${ }^{19}$ Self-efficacy is defined as the belief that one is capable of mobilising cognitive resources and courses of action to meet a given situational demand. ${ }^{20}$ In this study, it refers to the older persons' beliefs that they are able to adapt to the living in nursing homes. We measured the level of self-efficacy with two self-developed items (Cronbach's alpha $=0.822$ ). Stigma is defined as a person's perception that his or her behaviour or situation is disqualified from social acceptance or disapproved by social norms. ${ }^{21}$ We measured the older persons' perceived stigma with two self-developed items (Cronbach's alpha $=0.739$ ). Value-added service refers to the additional services provided by nursing homes besides the basic care, which include recreational activities and special care. ${ }^{22}$ We measured value-added service by using six specific items that asked the respondents how attractive it is for them if a nursing home offers recreational activities, daily living care, Traditional Chinese Medicine treatment, rehabilitation therapy, chronic disease management and private clinic, respectively (Cronbach's alpha $=0.934$ ). A Likert scale with response choices ranging from 1 (strongly disagree) to 5 (strongly agree) was used to rate intention, loneliness, life satisfaction, self-efficacy, perceived stigma and value-added service. The specific measurement items for self-efficacy, stigma and value-added service can be found in online supplementary appendix A. A three-item attitude scale ${ }^{23}$ was used to measure attitudes towards living in nursing homes. The scale was scored by asking the participants to rate the behaviour as 'good' versus 'bad', 'beneficial' versus 'harmful' and 'favourable' versus 'unfavourable' on a seven-point scale (Cronbach's alpha $=0.988$ ). Subjective norm was measured by a two-item scale ${ }^{23}$ capturing the 
influence of two major social referents: family members and friends. Each referent group's influence was rated on a scale ranging from 1 (definitely no) to 7 (definitely yes) (Cronbach's alpha=0.777).

\section{Statistical analysis}

We employed the structural equation modelling (SEM) approach to test the hypotheses by using AMOS V.21.0. The SEM analysis was performed in two steps. First, we tested a measurement model to validate the latent variables. Second, we tested a structural model to examine how intention to enrol in nursing home was influenced by the other variables. SEM is advantageous in estimating complex model involving many variables and able to estimate the fit between data and model. ${ }^{24}$ We used $\chi^{2} /$ $\mathrm{df}$, the Comparative Fit Index (CFI) and the root mean squared error of approximation (RMSEA) to test model fit adequacy where $\chi^{2} / \mathrm{df}<3$, CFI $>0.90$ and RMSEA $\leq 0.08$ indicate adequate fit. ${ }^{25}$ The demographic variables were included in the SEM analysis to control for their potential confounding effects.

\section{RESULTS}

\section{Participant characteristics}

Since the data were collected by a private interview with each participant, there were no missing values in our final data set. The sociodemographic information of the participants is summarised in table 1. A total of 641 older people were recruited. Their average age is 70.2 years, ranging from 60 to 95 . More than half $(62.2 \%)$ were female, and over one-third had received senior high school-level education or above. About $80 \%$ of the sample was married, with $76.0 \%$ of them living with their partners and only $10.8 \%$ living alone. In terms of monthly income, nearly one-third $(32.1 \%)$ had less than $¥ 3000$. The vast majority $(84.0 \%)$ had one or two children. Regarding self-reported health status, $34.6 \%$ respondents were above average and $26.7 \%$ below average. We compared the sample and population in terms of age, gender, education level and marital status, based on the Shanghai government's census data (http://www.shrca.org.cn). As table 2 shows, the sample and population have similar proportional distributions in age, education level and marital status, although the sample has a slightly higher percentage of female than the population. Overall, it is arguably justified that this sample is approximately representative of the Shanghai population of older persons.

\section{Model testing}

Bivariate correlations and mean values of the variables are shown in table 3. A confirmatory factor analysis was conducted to examine the factor structure of the latent variables. The model yielded a reasonable fit to the data, $\chi^{2}=308.77, \mathrm{df}=149, \chi^{2} / \mathrm{df}=2.072, \mathrm{CFI}=0.99$ and RMSEA $=0.041$. All of the measurement items are statistically significant at the 0.01 level, and all of them are above 0.70 except one item for value-added service which

\begin{tabular}{|c|c|c|}
\hline Sociodemographics & Count & Per cent $(\%)$ \\
\hline \multicolumn{3}{|l|}{ Sex } \\
\hline Male & 242 & 37.8 \\
\hline Female & 399 & 62.2 \\
\hline \multicolumn{3}{|l|}{ Age group (years) } \\
\hline $60-69$ & 333 & 52.0 \\
\hline $70-79$ & 212 & 33.0 \\
\hline$\geq 80$ & 96 & 15.0 \\
\hline \multicolumn{3}{|l|}{ Education level } \\
\hline Junior high school or less & 424 & 66.1 \\
\hline Senior high school or above & 217 & 33.9 \\
\hline \multicolumn{3}{|l|}{ Current marital status } \\
\hline Married & 514 & 80.2 \\
\hline Single, divorced or widowed & 127 & 19.8 \\
\hline \multicolumn{3}{|l|}{ No of children } \\
\hline None & 8 & 1.2 \\
\hline $1-2$ & 538 & 84.0 \\
\hline$\geq 3$ & 95 & 14.8 \\
\hline \multicolumn{3}{|l|}{ Living status } \\
\hline Living with partner only & 321 & 50.1 \\
\hline Living with children only & 80 & 12.5 \\
\hline Living with both partner and children & 166 & 25.9 \\
\hline Living alone & 69 & 10.8 \\
\hline Other & 5 & 0.8 \\
\hline \multicolumn{3}{|l|}{ Monthly income ( $¥)$} \\
\hline$\leq 3000$ & 206 & 32.1 \\
\hline $3001-4000$ & 276 & 43.1 \\
\hline$\geq 4001$ & 159 & 24.8 \\
\hline \multicolumn{3}{|l|}{ Health status } \\
\hline Very good & 31 & 4.8 \\
\hline Good & 191 & 29.8 \\
\hline Average & 248 & 38.7 \\
\hline Bad & 152 & 23.7 \\
\hline Very bad & 19 & 3.0 \\
\hline
\end{tabular}

is 0.66 . These results suggest that the measures have satisfactory convergent validity.

After the measurement model was validated, we estimated the structural model. As figure 1 shows, the structural model showed acceptable fit with the data, $\chi^{2} /$ $\mathrm{df}=2.948, \mathrm{CFI}=0.972$ and RMSEA $=0.055$. Attitude $(\beta=0.41$, $\mathrm{p}<0.01)$, subjective norm $(\beta=0.28, \mathrm{p}<0.01)$ and valueadded service $(\beta=0.16, p<0.01)$ were directly associated with enrolment intention, explaining $32 \%$ of variance in intention. Attitude was significantly influenced by loneliness $(\beta=-0.08, p<0.05)$, self-efficacy $(\beta=0.32, p<0.01)$ and stigma $(\beta=-0.24, p<0.01)$, while subjective norm was significantly influenced by life satisfaction $(\beta=-0.15, \mathrm{p}<0.01)$ and stigma $(\beta=-0.43, p<0.01)$. The variances explained in 
Table 2 Comparison between the study sample and the Shanghai population of older persons

\begin{tabular}{|c|c|c|}
\hline Sociodemographics & $\begin{array}{l}\text { Sample } \\
(n=641)\end{array}$ & $\begin{array}{l}\text { Population } \\
(n=4836000)\end{array}$ \\
\hline \multicolumn{3}{|l|}{ Sex (\%) } \\
\hline Male & 37.8 & 47.5 \\
\hline Female & 62.2 & 52.5 \\
\hline \multicolumn{3}{|l|}{ Age group (years) (\%) } \\
\hline $60-69$ & 52.0 & 59.1 \\
\hline $70-79$ & 33.0 & 24.2 \\
\hline$\geq 80$ & 15.0 & 16.7 \\
\hline \multicolumn{3}{|l|}{ Education level (\%) } \\
\hline Junior high school or less & 66.1 & 69.5 \\
\hline Senior high school or above & 33.9 & 30.5 \\
\hline \multicolumn{3}{|l|}{ Current marital status (\%) } \\
\hline Married & 80.2 & 77.6 \\
\hline Single, divorced or widowed & 19.8 & 22.4 \\
\hline
\end{tabular}

attitude and subjective norm are $24 \%$ and $21 \%$, respectively. Finally, loneliness and life satisfaction $(\beta=-0.31$, $\mathrm{p}<0.01)$, self-efficacy and stigma $(\beta=-0.47, \mathrm{p}<0.01)$ were interrelated. The demographic variables were controlled for in the SEM model to remove confounding effects. The results showed that age $(\beta=-0.05, p>0.05)$, gender $(\beta=0.08, p>0.05)$, education $(\beta=0.02, p>0.05)$, marital status $(\beta=-0.001, p>0.05)$, income $(\beta=0.08, p>0.05)$ and health status $(\beta=-0.05, p>0.05)$ have no significant effects on enrolment intention.

\section{DISCUSSION}

Overall, our findings reveal that the older people's intention to enrol in nursing homes is determined by their attitude towards nursing homes, subjective norm and value-added service of nursing homes. Loneliness reduces intention by negatively impacting attitude. Self-efficacy enhances intention by positively impacting attitude. Life satisfaction reduces intention by negatively impacting subjective norm. Perceived stigma reduces intention by negatively impacting both attitude and subjective norm. All of our hypotheses are supported. These findings have significant implications for research and practice in the area of eldercare, particularly in China.

This study fills an important gap in the literature of long-term care for older people. That is, the sociocognitive factors that influence older people's nursing home enrolment in Asian countries have not been thoroughly understood. Past research has mainly focused on demographical, socioeconomic and physiological factors, neglecting the importance of older people's cognition. ${ }^{8-10}$ This lack of research is particularly pronounced in large cities in China where eldercare is a pressing problem and older people are reluctant to live in nursing homes, even when they need professional healthcare and living assistance. ${ }^{26}$ Therefore, more research is also needed to show that living in nursing homes is an appropriate behaviour to target as opposed to better supporting living at home with increase home care services. In addition, it is unclear how the cultural and affective factors such as loneliness, life satisfaction, self-efficacy and stigma interact with cognitive factors to influence older people's intention to enrol in nursing homes. The findings of this study help to shed light into these vaguely understood areas.

Our findings confirm that TRA is an acceptable theoretical foundation for this study. In line with past research, ${ }^{16}$ attitude was found to be the most powerful predictor of nursing home use. It appears that having favourable attitudes towards nursing homes does increase the odds of using nursing home services. The significance of subjective norm corroborates prior research which found that in Eastern countries, older persons' perceptions of what their families, friends, ministers and communities wanted them to choose would influence their decision to enrol in a nursing home. ${ }^{26}{ }^{27}$ A study on Japanese Americans estimated that $85.8 \%$ of older people would do what their family wanted them to do and $50.6 \%$ of them would follow their friends' opinions. ${ }^{28}$ This might be due to the collectivistic culture in Eastern Asia which makes people more acquiescent to the influence of their social contacts.

\begin{tabular}{llllllllll}
\hline \multicolumn{1}{l}{ Table 3} & \multicolumn{1}{l}{ Bivariate correlations, mean values $(\mathrm{M})$ and SD of study variables $(\mathrm{n}=641)$} \\
\hline Variable & $\mathbf{M}$ & $\mathbf{S D}$ & $\mathbf{1}$ & $\mathbf{2}$ & $\mathbf{3}$ & $\mathbf{4}$ & $\mathbf{5}$ & $\mathbf{6}$ & $\mathbf{7}$ \\
\hline 1. Loneliness & 1.99 & 1.15 & & & & & & & \\
2. Life satisfaction & 4.12 & 0.93 & $-0.29^{\star \star}$ & & & & & & \\
3. Self-efficacy & 3.38 & 1.00 & -0.02 & 0.04 & & & & & \\
4. Stigma & 1.95 & 0.92 & $0.15^{\star \star}$ & $-0.08^{\star}$ & $-0.35^{\star \star}$ & & & & \\
5. Attitude & 4.72 & 1.99 & $-0.10^{\star \star}$ & 0.01 & $0.40^{\star \star}$ & $-0.30^{\star \star}$ & & & \\
6. Subjective norms & 4.11 & 1.57 & -0.01 & $-0.11^{\star \star}$ & $0.27^{\star \star}$ & $-0.26^{\star \star}$ & $0.44^{\star \star}$ & & \\
7. Value-added services & 4.15 & 1.00 & -0.08 & $0.09^{\star}$ & $0.30^{\star \star}$ & $-0.25^{\star \star}$ & $0.35^{\star \star}$ & $0.18^{\star \star}$ & \\
8. Intention & 3.15 & 1.26 & -0.06 & -0.03 & $0.33^{\star \star}$ & $-0.27^{\star \star}$ & $0.57^{\star \star}$ & $0.42^{\star \star}$ & $0.33^{\star \star}$ \\
\hline
\end{tabular}

${ }^{*} \mathrm{P}<0.05$ (two tailed).

${ }^{* \star} \mathrm{P}<0.01$ (two tailed). 
Loneliness is an unpleasant and distressing experience caused by the subjective assessment that one's relationships with others are unsatisfactory. ${ }^{29}$ Older people feel lonely mostly because it is hard for them to maintain intimate relationships with their family members, friends or relatives. ${ }^{13}$ Their feeling of loneliness is unlikely to decrease if they move into a nursing home. Even worse, living in a nursing home can further separate them from their family and friends. Although a study conducted in the USA found that lonely older persons were more likely to enrol in a nursing home so as to enhance social network and reduce loneliness, ${ }^{13}$ another study in Spain found that institutionalised older adults were even more likely to feel lonely compared with people living at home. ${ }^{30}$ Our study confirmed that for the older persons in Shanghai, loneliness might result in a negative attitude towards nursing home placement and reduce their intention to enrol in nursing homes.

Older people who perceive higher life satisfaction usually have a harmonious family and can receive instrumental support as well as financial support from their children. ${ }^{14}$ They enjoy living closely with their family, and their family would oppose the idea for them to live in nursing homes due to the traditional Chinese cultural value. As a result, the older people who are satisfied with life are unlikely to intend to live in nursing homes via the influence of subjective norm. To date, life satisfaction has mostly been examined as an outcome of living in nursing homes and the findings were mixed. A study showed that placement of residence was not related to older persons' expression of life satisfaction in Japan. ${ }^{31}$ Yet, in the USA, those who lived in nursing homes reported lower life satisfaction than community-dwelling older people. ${ }^{32} \mathrm{On}$ the contrary, a study in China showed living in a nursing home was associated with increased life satisfaction. ${ }^{33} \mathrm{Few}$ studies have investigated life satisfaction as an antecedent of nursing home admission. This paper makes a contribution by showing the indirect effect of life satisfaction on intention to live in nursing homes.

Self-efficacy entails the confidence in one's own ability to undertake the target behaviour. People generally have strong motivation towards tasks where self-efficacy is high and thus strongly influences a person's behavioural choice. ${ }^{15}$ From the perspective of theory of planned behaviour, self-efficacy is equivalent to perceived behavioural control and should have a direct effect on behavioural intention. ${ }^{34}$ However, in this research, the target behaviour is to enrol in a nursing home. We did not measure self-efficacy of enrolling in nursing homes; instead, we measured older persons' self-efficacy of making adjustments to nursing homes. Hence, there is a mismatch between the target behaviour for self-efficacy and the target behaviour for intention, and a direct link between them is not expected. Based on the study context in China, we contend that even if older persons have high self-efficacy of living in nursing homes, their intention to enrol in a nursing home is not necessary stronger. A more reasonable rationale is that if the older persons are confident about their capability of adapting to the life style in nursing homes, they would have a positive attitude towards living in nursing homes.

Perceived stigma is a sociopsychological response of individuals who possess characteristics that are devalued in a particular social context. ${ }^{35}$ Traditional norms in China, such as familism and filial piety, treat placing older people in a nursing home as non-filial practice. This would put criticism and pressure onto family members for abandoning their older parents, which could be a major barrier to nursing home admission. A study in Taiwan ${ }^{16}$ found that those who do not regard their children as lacking in filial piety would prefer living in institutions for long-term care. The traditional Chinese society has a heavy reliance on family members to provide eldercare. Nursing homes were deemed only for those without family and income, and living in nursing homes was considered a shame. Family-based care is consistent with the strong collectivistic culture in China, which has probably contributed to the underutilisation of formal nursing home care services.

\section{Implications for practice}

Our findings have implications for practice in public health and policy in China and other Eastern Asian countries that share similar sociocultural characteristics. This study may inform health policy-makers and nursing home managers about the importance of reaching out to the community to establish a positive image of nursing homes so that a favourable attitude can be developed towards living in nursing homes. Our findings suggest that nursing homes can promote older people's interest by taking several actions. First, they can show the public their capability to provide high-quality care and create an enjoyable and safe environment for older people. Second, they can demonstrate how residents get along with each other and convince older people that loneliness will not be a concern. Finally, they can invite older people to have tours in the nursing home to show how easily it is to adapt to the life style.

As is shown in our study, the older persons' social contacts, including family members and friends, play an important role in influencing their decision to enrol in nursing homes. Both the older person and his or her family tend to experience mixed emotions in the process of deciding whether to send the older person to a nursing home. Perceived stigma can be a huge psychological obstacle to overcome. Here public policy-makers can step in to nurture a social environment in which living in nursing homes is nothing shameful. Instead, it should be an acceptable, even a preferred, way to spend the rest of one's life. Such public education programmes will help older people develop positive attitude and normative beliefs about nursing homes and ultimately enhance their intention of enrolment.

\section{Limitations}

Despite the above interesting findings, this study also has several limitations. First, the variables in our research 
model are not comprehensive. While the selection of these variables is supported by literature and interviews with older persons in Shanghai, there are a number of other variables that can potentially influence older persons' intention to enrol in nursing homes. One possible approach is to apply the Theoretical Domains Framework (TDF) which includes 14 domains and 84 factors to explain behavioural change. ${ }^{36}$ However, the complexity of such a large framework goes beyond the scope of this study. Besides, the TDF does not offer testable hypotheses, ${ }^{36}$ and more complex models do not necessarily outperform simpler models. It would be interesting for a future study to apply TDF to investigate older persons' nursing home enrolment intention. Second, although intention to enrol in nursing home has often been used as a proxy measure of actual behaviour, all intentions are not always carried out. ${ }^{12}$ Factors associated with intention in this study may not turn into actual behaviour. Due to the use of cross-sectional observational design, causal inference and generalisability are not possible. Further research using a longitudinal research design to track the intention and actual behaviours would generate more insights. Finally, selection bias might be a concern for our data. Since we recruited patients from six community health service centres in 2 weeks, the location and timing of data collection could limit the representativeness of the sample. For example, the older persons visited the community health centres to seek medical care, and this commonality might systematically influence their intention to enrol in nursing homes. This concern is partially alleviated by the approximate similarity between our sample and the population of Shanghai older persons in terms of age, education level and marital status.

\section{CONCLUSIONS}

The study provides insights regarding influencing factors of elder people's intention to enrol in nursing homes. Based on the findings, the following measures are recommended to motivate older people to enrol in nursing homes. First, public education can be carried out to change the stereotypical view of nursing homes in the traditional Chinese culture. Both the parents and their adult children should be aware that institutional eldercare is a viable choice for formal care and nothing to be ashamed of. Second, nursing homes can reach out to older people to show them how easy it is to live in a nursing home. With heightened self-efficacy, the older people are more likely to enrol in nursing homes. More research is needed to evaluate whether such strategies can effectively increase the older people's intention to enrol in nursing homes.

Contributors ML, YX, ZZ and HL designed the study. ML, SZ, YD, DM, WD, KQ and YF collected data. ML, YX and HL conducted data analysis and wrote the manuscript. ML, YX, ZZ and HL proofed the final manuscript.

Funding This research was partially supported by the Public Health Action Plan 2015-2017 (GWIV-25).
Competing interests None declared.

\section{Patient consent Obtained.}

Ethics approval The study was approved by the Ethics Committee of the School of Public, Shanghai Jiao Tong University in September 2016.

Provenance and peer review Not commissioned; externally peer reviewed.

Data sharing statement Dataset available on request. Please contact the corresponding authors.

Open access This is an open access article distributed in accordance with the Creative Commons Attribution Non Commercial (CC BY-NC 4.0) license, which permits others to distribute, remix, adapt, build upon this work non-commercially, and license their derivative works on different terms, provided the original work is properly cited, appropriate credit is given, any changes made indicated, and the use is non-commercial. See: http://creativecommons.org/licenses/by-nc/4.0/.

\section{REFERENCES}

1. Yang SL, Zheng-Long LI. The impact of aging population on the burden of elderly in Shanghai. Northwest Population Journal 2010;31:61-6.

2. SRCo A. Statistics of old people 's population and aging in Shanghai in 2016. Shanghai, 2017.

3. Sciences SAoS. Shanghai academy of social sciences blue book: 2020 Shanghai "demographic dividend" will disappear. Shanghai, 2016.

4. Swan JH, Kitchener M, Harrington C. Medicaid nursing facility rates, capacity, and utilization: a structural analysis. Soc Work Public Health 2009;24:380-400.

5. Liu C, Feng Z, Mor V. Case-mix and quality indicators in Chinese elder care homes: are there differences between government-owned and private-sector facilities? J Am Geriatr Soc 2014;62:371-7.

6. Aging SRCO. Investigation on nursing care and willingness to care for old people in Shanghai, 2017.

7. Andel R, Hyer K, Slack A. Risk factors for nursing home placement in older adults with and without dementia. J Aging Health 2007;19:213-28.

8. Nuutinen M, Leskelä RL, Suojalehto E, et al. Development and validation of classifiers and variable subsets for predicting nursing home admission. BMC Med Inform Decis Mak 2017;17:39.

9. Johnson RA, Schwiebert VB, Rosenmann PA. Factors influencing nursing home placement decisions: the older adult's perspective. Clin Nurs Res 1994;3:269-81.

10. Zhan HJ, Liu G, Guan X. Willingness and availability: explaining new attitudes toward institutional elder care among Chinese elderly parents and their adult children. J Aging Stud 2006;20:279-90.

11. Bell CL, LaCroix AZ, Desai M, et al. Factors associated with nursing home admission after stroke in older women. J Stroke Cerebrovasc Dis 2015;24:2329-37.

12. Ajzen I. From intentions to actions: a theory of planned behavior. In: Kuhl J, Beckmann J, eds. Action control: from cognition to behavior. Berlin Heidelberg: Springer, 1985:11-39.

13. Russell DW, Cutrona CE, de la Mora A, et al. Loneliness and nursing home admission among rural older adults. Psychol Aging 1997;12:574-89.

14. $\mathrm{Xu} \mathrm{L,} \mathrm{Chi} \mathrm{I.} \mathrm{Life} \mathrm{satisfaction} \mathrm{among} \mathrm{rural} \mathrm{Chinese} \mathrm{grandparents:} \mathrm{the}$ roles of intergenerational family relationship and support exchange with grandchildren. Int J Soc Welf 2011;20(1/2):S148-59.

15. Lee LL, Arthur A, Avis M. Using self-efficacy theory to develop interventions that help older people overcome psychological barriers to physical activity: a discussion paper. Int J Nurs Stud 2008;45:1690-9.

16. Chung $\mathrm{MH}$, Hsu N, Wang YC, et al. Factors affecting the longterm care preferences of the elderly in Taiwan. Geriatr Nurs 2008;29:293-301.

17. Archambault PM, McGavin C, Dainty KN, et al. Recommendations for patient engagement in patient-oriented emergency medicine research. CJEM 2018;20:435-42.

18. Russell DW. UCLA Loneliness Scale (Version 3): reliability, validity, and factor structure. J Pers Assess 1996;66:20-40.

19. Pavot W, Diener E. Review of the satisfaction with life scale. Psychol Assess 1993;5:164-72.

20. Wood R, Bandura A. Impact of conceptions of ability on selfregulatory mechanisms and complex decision making. J Pers Soc Psychol 1989;56:407-15.

21. Goffman E. Stigma: notes on the management of spoiled identity. Am J Sociol 1969;45:642. 
22. Wu M, Li SX, Zhang NJ, et al. Nursing home research in Jinan, China: a focus group approach. Int J Public Pol 2012;8:21-30.

23. Fishbein M. A theory of reasoned action: some applications and implications. Nebr Symp Motiv 1980;27:65-116.

24. Kline RB. Principles and practice of structural equation modeling. 2nd edn. New York: Guilford Press, 2005.

25. Barrett P. Structural equation modelling: adjudging model fit. Pers Individ Dif 2007:42:815-24.

26. Kim H, Choi WY. Willingness to use formal long-term care services by Korean elders and their primary caregivers. J Aging Soc Policy 2008;20:474-92.

27. Mattimore TJ, Wenger NS, Desbiens NA, et al. Surrogate and physician understanding of patients' preferences for living permanently in a nursing home. J Am Geriatr Soc 1997;45:818-24.

28. McCormick WC, Uomoto J, Young $\mathrm{H}$, et al. Attitudes toward use of nursing homes and home care in older Japanese-Americans. J Am Geriatr Soc 1996;44:769-77.

29. Donaldson JM, Watson R. Loneliness in elderly people: an important area for nursing research. J Adv Nurs 1996;24:952-9.
30. Prieto-Flores ME, Forjaz MJ, Fernandez-Mayoralas G, et al. Factors associated with loneliness of noninstitutionalized and institutionalized older adults. J Aging Health 2011;23:177-94.

31. Given JE, Range LM. Life satisfaction and death anxiety in elderly nursing home and public housing residents. J Appl Gerontol 1990;9:224-9.

32. Gueldner SH, Loeb S, Morris D, et al. A comparison of life satisfaction and mood in nursing home residents and communitydwelling elders. Arch Psychiatr Nurs 2001;15:232-40.

33. Guan J, Li H, Sun H, et al. The impact of a discrepancy between actual and preferred living arrangements on life satisfaction among the elderly in China. Clinics 2015;70:623-7.

34. Fishbein M, Cappella JN. The role of theory in developing effective health communications. J Commun 2006;56(suppl_1):S1-17.

35. Zimmerman S, Dobbs D, Roth EG, et al. Promoting and protecting against stigma in assisted living and nursing homes. Gerontologist 2016;56:535-47.

36. Atkins L, Francis J, Islam R, et al. A guide to using the theoretical domains framework of behaviour change to investigate implementation problems. Implement Sci 2017;12:77. 